\title{
The cenological paradigm in the designing of the digital twin of the human capital structure
}

\author{
Alexander Kuzminov ${ }^{1, *}$, Alexandra Voronina $^{2}$, Margarita Bezuglova ${ }^{3}$, and Tatiana \\ Medvedskaya ${ }^{3}$ \\ ${ }^{1}$ Rostov State University of Economics, 69, B. Sadovaya Str., Rostov-on-Don, 344002, Russia \\ ${ }^{2}$ Rostov State Transport University, 2, Rostovskogo Strelkovogo Polka Narodnogo Opolcheniya Sq., \\ Rostov-on-Don, 344038, Russia \\ ${ }^{3}$ Don State Technical University, 1 Gagarina Sq., Rostov-on-Don 344000, Russia
}

\begin{abstract}
The object of research in this article is the category "human capital" as the foundation for the development of generations and the state in the digital future. This category is directly dependent on the complication of economic systems, changes in the information space and society digitalization. Highlighting of the features of the political and economic nature of "human capital" is possible from the standpoint of its assessment as a key state resource, the impact indicators of which are a combination of classical and newly identified information parameters. In an effort to expand the understanding of the phenomena of institutional changes, of economics and public administration, the multilevel causal model is proposed. The forces of the model act in two directions: macro-causes that explain behaviour at the micro level, and the microlevel laws affecting the entire system at the macrolevel. As a part of the development of interdisciplinary research, the article proposes a new conceptual approach to the formalization and management of the human capital structure. The basis of integration is cenological theory that allows to formalize the system of macro-rules ensuring the stability of complex systems, in particular, of the generations in the information space. The basic research paradigm is proposed and promising results are determined on the example of stratification of human capital parameters.
\end{abstract}

\section{Introduction}

Under high dynamics of structural information changes in the economy and the society, the importance of research to determine macro-rules and achieve macro-order that characterize these information transformations is increasing. A significant number of specialists recognize the promising character of research into the theory of human capital in modern conditions from the standpoint of digital institutionalism.

Digitalization has provided a rebirth of the interest in institutions in organizational theory and economic sociology. The emphasis of causal reasoning has shifted from research focused on agents (economic and institutional subjects) to patterns that mediate a person's relationship with his institutional environment.

\footnotetext{
*Corresponding author: caas@mail.ru
} 
Thus, the existence of a multilevel causal model including the relationship between the subinstitutional area of information action with specific socio-economic relations and the meso- and macroinstitutional environment as a whole is confirmed. They explain the dynamics and composition of numerous changes and transformations. In this model, some system-wide norms link the microcosm of individual personalities and social groups and the broader institutional environment. The interdisciplinary approach and cumulative empirical efforts should provide an opportunity to identify the common features and conditions that form the processes of such institutional changes.

In a number of fundamental studies, it is proposed to formalize the structure of human capital through conceptual epistemological integration, substantiation of the macroeconomic influence of parameters, substantiation of regional influence, from a system-wide standpoint, and value assessment at the micro-level. The listed approaches expand the understanding of the human capital structure, but methodologically they increase the uncertainty. A review of scientific literature has shown that studies related to various aspects of understanding of the human capital structure are widely represented in foreign publications, but they also cannot be called completed.

There is a considerable variety of general approaches and concepts in which parameters are presented as a part of a system of strategic or rigorous empirical analysis. Numerous empirical studies have made it possible to substantiate the need to use a complex of previously unobservable parameters in assessing the human capital structure, such as: the level of unemployment, the structure of working hours [2], features of labour motivation [3], nationality (race) [4], other non-economic parameters [5], generations, etc.

The directions of socio-economic phenomena modelling in the context of digital transformation of systems are represented by a number of fundamental studies, such as the analysis of the stochastic effect of endogenous factors on them, the representation of human capital as a nonlinear dynamic system, structural equations in sociology [6], the method of mathematical generalizations [7]. Attempts of interdisciplinary modelling of the human capital structure using the data obtained by the Big Data analytics method have been implemented by some research teams in Russia [8, 9, 10], the USA [11], Romania and Italy [12], Ireland and Great Britain [3], etc.

The scientific problem lies in the fact that the listed works do not answer a number of questions related to the nature of the formation and dynamics of the structure of complex social systems, they do not provide the possibility of interdisciplinary synthesis; they are also characterized by difficulty of structuring, intra-paradigm problems (narrowness of the subject area, lack of mathematical tools, linearity of development), and by the problems of coupling of the research models.

An extensive analysis of the scientific research aimed at studying human capital indicates that the understanding of many aspects of research is far from being complete also due to the lack of quality data and their intellectual analysis. Many models are focused on limited probabilistic samples; besides, generally recognized analysis tools have not been developed; the negative social nature of the procedures for the classical metrification of human capital in the long-term perspective is noted.

To solve this problem, in the first part of the article, the fundamental ideas of integration are formed, based on the epistemological unity of learning the necessary properties and conditions of collective human life, arising from the nature of functioning in the newly emerging categories of social and economic interaction, characterized by complexity and diversity, which prevents or complicates the use of classical approaches and research methods. The second part is devoted to the formalization of the research model for considering sociocenoses, reflecting the features of the formation of human capital in modern conditions, where the possibility of representation of the capital structure in terms of the theory of cenoses is taken as a methodological basis. The third part of the article presents 
some patterns of the formation of sociocenoses. In the conclusion, the main elements of the new paradigm for the study of human capital, the prospects for the practical implementation of the proposed approach are given.

\section{Objectives and foundations of interdisciplinary synthesis}

To examine a new institution for the stratification of modern society, let us consider the category of "human capital cenosis" as the foundation for the development of society and the state. It is directly dependent on the complication of economic systems, production and social relations. The study of the state of human capital, its structure, prospects and development dynamics is one of the most urgent tasks of the social sciences. Scientific research in this area can make an invaluable contribution to improving the most optimal system of public administration and management of human capital in modern Russia, ensuring long-term development and competitiveness in the world economy. Taking into account the complex nature of the research objective, it is required to deploy research in a multifactorial plane, as the complexly structured object - "human capital in macroeconomic systems" - requires itself [1]. The study of human capital will need combined efforts of a number of specialized sciences - economics, political science, sociology and philosophy, basing on the fundamental concepts of the Theory of Cenoses, which, in this case, should play the role of a systemforming factor of interdisciplinary study. As a result of integration, a synthetic methodological paradigm can be developed, it can provide an increase in the ability to understand the patterns of formation and structuring of human capital in various conditions.

The approach proposed in the article is a continuation of the discourse existing in Russian science. For e[ample, the peculiarities of the current state of human capital and the tasks of the development of the theory and methodology that take into account the process of its qualitative transformation underlie the studies of the Institute of Sociology of the Russian Academy of Sciences, the Centre of Modern Technologies for the Development of Human Capital of Moscow State University, the Higher School of Economics, the Institute of SocioEconomic Development of Territories of the Russian Academy of Sciences.

To implement this scientific task, it will be necessary to substantiate the possibility of synthesizing research models within the framework of a cenological paradigm; to identify the parameters that characterize modern human capital; to adapt the existing approaches of identification and description of the parameters of the human capital structure at all levels of management of cenoligical laws; to substantiate - both theoretically and empirically - the possibility of species and rank-species description of the parameters of human capital and determine the parameters of the macro-order, which are understood as "criteria for the cenosis' sustainability."

The result of the research will be presented as the technology of species clustering of complex social systems of the cenotic type in the parameters that characterize the state of the human capital structure. This clustering will make it possible to form the optimal invariants of designing social systems that ensure sustainable development based on the automatic launch of self-organization processes.

\section{Methodology of the research}

\subsection{Conceptual foundations of taxonomy}

To implement the research objectives, a participatory approach will be required, which includes a sequence of stages:

1) creation of the structure of scenario; 
2) search for drivers;

3) choice of drivers (and indicators);

4) development of the hypotheses;

5) evaluation and testing of the hypotheses;

6) generalization.

Scientific research in the field of such macro-rules and the content of human capital is presented nowadays in two dimensions:

1) formation of the composition of key parameters for subsequent management;

2) development of optimization and forecasting models.

It is necessary to formulate a number of scenarios covering a wide range of thematic and methodological knowledge and providing an interdisciplinary synthesis. In this case, the scenarios must be contextualized within the framework of cenological theory.

Basing on the assumption that modern social structures increasingly correspond to the category of "complex system", we use the interdisciplinary analytical framework of the study of such systems to develop new models. It is also necessary to implement an algorithm for the scientific synthesis of separate areas of research of complex systems, including cognitive analysis, Bayesian decision-making theory, combined within the framework of a cenological approach, the effective interdisciplinarity of which is the result of describing certain species properties of complex-structured communities located and functioning in time and space as a single whole object, and which can be observed and statistically investigated. This integrity consists of elements that do not have mutually conditioning relationships. The elements differ in their parameters, and most of the complex systems possess these characteristics.

The ontological basis of this stage of research is the analytically confirmed possibility of interdisciplinary integration of models. The models are used in the analysis of complex systems on a structural and topological basis. The scientific basis for constructing an integrative model was created by numerous studies of scientists, generalizing the ideas about the constructive content and methodological disciplinary unity of economic, technical and psychological knowledge. This knowledge is expanded by the combination of related scientific fields, such as: Kutyrev's (1994) biological analogies in the engineering, the idea of Weber and Debue (1996) to use the concept of natural selection in the economics, Arthur's (2015) theory of complexity, Llerand's and Lorenz (2005) cumulative causality, Zagler's (2009) growth theory, Ropol's (2017) theories of interdisciplinary synthesis of engineering and technology.

The empirical base of interpreted decisions can be formed using the logic of "industrial models", the integration of which is provided through the technological embedding of the tools of cognitive and cenological analysis.

\subsection{Methodology for the study of social cenoses}

We proceed from the assumption that a special feature of cenoses is their popularity, and this makes it possible to apply evolutionary and ecological laws for the analysis and modelling of many social systems. In the proposed concept, the diverse content of the parameters of human capital mediates the possibility of differentiating it according to species characteristics. The analogues are presented in biology and technology, where "species" is understood as a stable set of carriers of common characteristics of diverse elements of human capital.

The design of the required key images of a person (society, generations) in order to ensure the sustainable development of Russia is carried out by means of a purposeful impact on the processes of species self-organization, which occurs in accordance with the laws of development of cenoses and in this paradigm will have the highest level of efficiency at minimum cost. The influence of the state on the parameters required from the standpoint of 
sustainability will lead to the recombination of the human capital structure and the formation of an optimal species structure that increases the total capabilities of the society. We are going to consider human capital as a part of jointly evolving complex systems:

1) sociocultural;

2) creative;

3) political;

4) environmental;

5) economic.

The systems are linked through interactions and feedback, and are resource constrained in an investment context. The systems form a co-evolutionary model operating on the basis of the following mechanisms: competition, mutual development, mutual influence, mutual restriction. This allows us to consider the social cenosis in the context of the interrelationships of the general rules of self-organization.

To determine research scenarios, it is advisable to use the patterns of interpreted analytics, which is developed in a number of scientific fields. This is an epistemological approach to modelling landscapes of complex communities, which is the focus of the works by Weisberg and Muldoon, formalizing the micro-mechanisms of cognitive diversity, coordination and efficiency of solving complexity. This is also a formalized Hardt's conceptual apparatus for managing complexity, "models of understanding" of economic reality [13], and identifying links between "design and measure".

J. Johnson [14] in his study shows the species distribution by age categories of Internet users worldwide in 2019 (see Fig. 1).

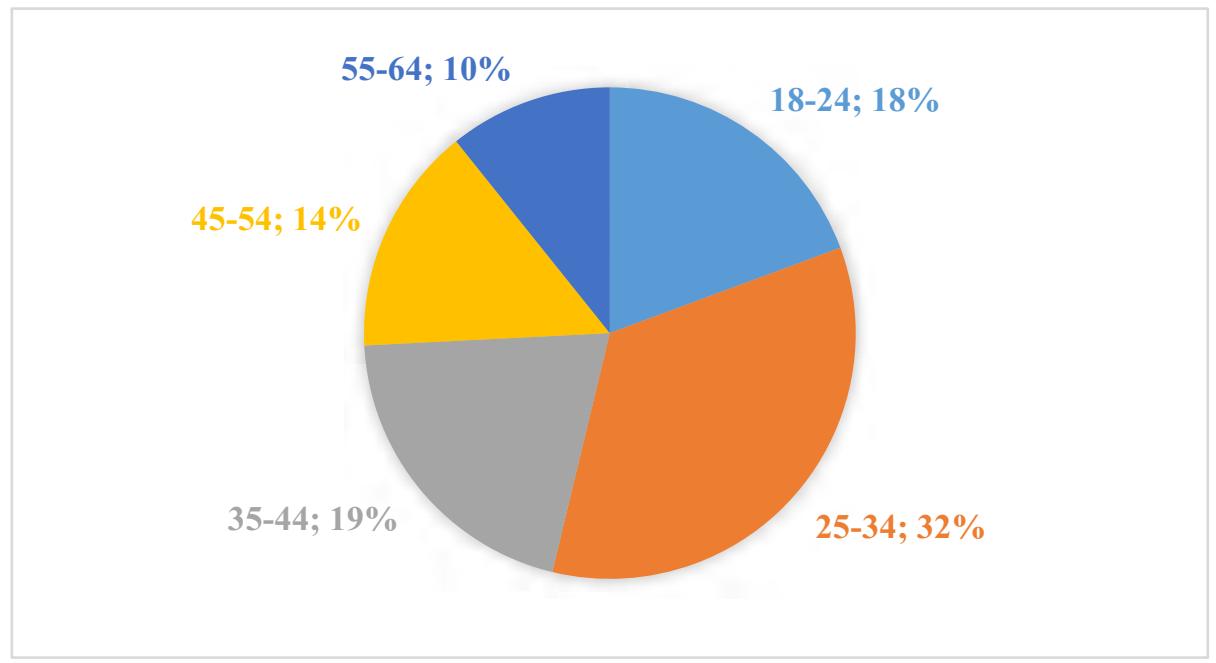

Fig. 1. Distribution of Internet users worldwide by age categories.

As of 2019, a third of online users worldwide were between the ages of 25 and 34 . Website visitors in this age group make up the largest group of online users worldwide. In addition, $18 \%$ of online users worldwide were between the ages of 18 and 24 . However, there are many unreported users under the age of 18.

In his research, J. Hawksworth formalized the possible trajectories of the automation influence on various profession groups [15] (see Fig. 2), where significant differences in time are visible. 


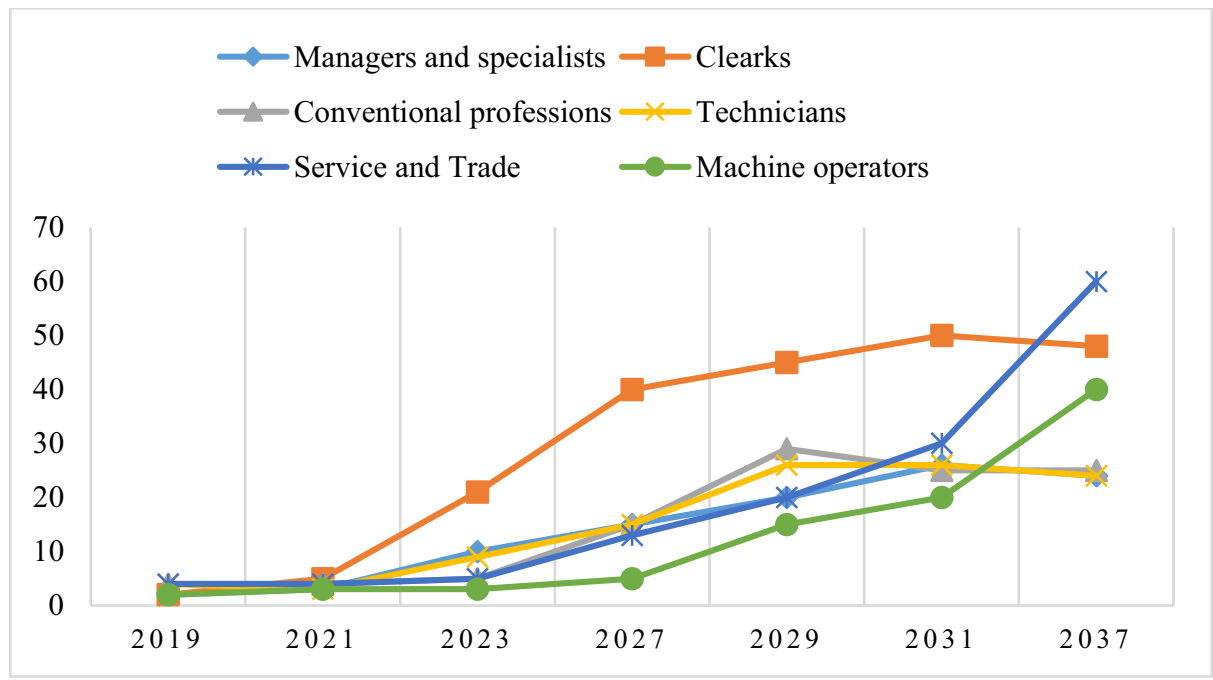

Fig. 2. Potential automation influence on the profession groups (percentage of replacement) [15].

There is a complex of interpretable solutions for the models of interdisciplinary research in socio-economic sciences that experience limitations associated with the permanent appearance of new endogenous explanatory variables, unobservable limitations and systematic deviations in the results.

Thus, the key to a purposeful change of the human capital structure as a cenosis in the interests of the governing system (society) is not a search of the methods, for example, making people learn information technologies, but a search of the ways that allow and encourage the development and application of the rules, aimed at choosing the direction of activity that is potentially beneficial and allows to distribute meso-rules for the entire social population in the information space.

\section{Discussion}

The peculiarity of the proposed approach is the use of a fundamentally new methodological solution for analysing the state and prospects of human capital development. Its essence lies in the use of the methodological relationship between the theory of cenoses, on the one hand, and the interdisciplinary methodology of the social sciences, on the other hand.

The idea is based on the hypothesis that as a result of the complication of modern society, the human capital structure has received signs of a community, which can be considered by classification signs as a cenosis. That is, the social system can be interpreted using a species analysis tool that determines the patterns of distribution of human capital parameters by individuals and social groups.

In the context of an unstable and frequently changing topology of human capital parameters, the proposed approach will solve the scientific problem associated with the need to improve the quality of analysis and forecasting of social sets. These sets are characterized by a large number of parameters, an interdisciplinary nature of formation, a complex structure, and the presence of a significant number of non-equilibrium elements. The approach will help to realize the possibility of constructing new key images to ensure sustainable development of Russia, to solve the problems of forming state identity, and perception of the future of Russia by various social groups.

Taking into account the complex nature of the scientific task, the authors of the study intend to expand the study in a multifactorial plane in the future, since this is required by the 
complexly structured object itself - "human capital in macroeconomic systems". Its study will necessarily entail combining the efforts of a number of special sciences - economics, political science, sociology and psychology, based on the fundamental concepts of the Theory of Cenoses.

\section{Conclusion}

The result of the proposed scientific integration is the institutionalization of social cenoses in the information space. The methodology will provide knowledge of the necessary properties and conditions of collective human life arising from the nature of human functioning in the new emerging informational categories of social and economic interaction. The categories will differ in complexity and variety that will influence the use of classical approaches and research methods. The category "human capital" is the foundation for the development of society and the state in the digital information space, which is directly dependent on the complication of economic systems, industrial and social relations. The study of the human capital state, its complex structure, prospects and dynamics of development is one of the most urgent tasks of the social sciences. Scientific research in this area can provide an invaluable contribution to improving the optimal system of public administration and management of human capital, ensuring long-term development and competitiveness in the world economy.

The proposed interdisciplinary approach makes it possible to assess how these rules act indirectly and simultaneously, being conditioned by the existing vector of development of the entire complex system - social cenosis. It should be noted that an interdisciplinary acmeological approach plays an important role in a deeper understanding of the processes of formation and functioning of human capital. This approach helps to identify highly productive groups as a system-forming factor in futuropractice.

\section{References}

1. Shabunova. A.A., et al.: Problems of state governing efficiency. Human capital of the territories: problems of forming and use (Institute of Socio-Economic Development of Territories of the Russian Academy of Sciences, Vologda, 2013)

2. Taiji, R.: Social Science Research 85, 102370 https://doi.org/10.1016/j.ssresearch.2019.102370

3. Lenihan, H., McGuirk, H., Murphyc, K.R.: Research Policy 9(48), 103791 (2019) https://doi.org/10.1016/j.respol.2019.04.015

4. Ressler, R.W., Ackert, E., Ansari, A., Crosnoe, R.: Social Science Research 85, 102364 (2020) https://doi.org/10.1016/j.ssresearch.2019.102364

5. Okumura, R., Deguchi, H.: Evolutionary and Institutional Economics Review 17 (2020) https://doi.org/10.1007/s40844-020-00166-1

6. Meulemana, B., Roosmab, F., Abtsb, K.: Social Science Research 85, 102352 (2020) https://doi.org/10.1016/j.ssresearch.2019.102352

7. Kottaridi, C, Louloudi, K., Karkalakos, S.: International Business Review 2(28), 375390 (2019) https://doi.org/10.1016/j.ibusrev.2018.10.008

8. Ketova, K.V., Romanovsky Yu. M., Rusyak I.G.: Computer research and modelling 2(11), 329-342 (2019)

9. Voronina, A.V., Logvinova, I.K.: Science and education: business and economics; entrepreneurship; law and management 3(130), 48-50 (2021) 
10. Kuzminov, A.N., Korostieva, N.G., Dzhukha, V.M., Ternovsky, O.A.: Contemporary Issues in Business and Financial Management in Eastern Europe 100, 61-70 (2018) https://doi.org/10.1108/S1569-375920180000100008

11. Hamilton, R.H., Sodeman, W.A.: Business Horizons 63, 85-95 (2020) https://doi.org/10.1016/j.bushor.2019.10.001

12. Nicolaescu, S.S. et al.: Future Generation Computer Systems 111, 654-667 (2020) https://doi.org/10.1016/j.future.2019.09.048.

13. Chater, N., Loewenstein, G.: Journal of Economic Behavior \& Organization 126(B), 137-154 (2015) ttps://doi.org/10.1016/j.jebo.2015.10.016.

14. Statista. https://www.statista.com/statistics/272365/age-distribution-of-internet-usersworldwide/, last accessed 2021/03/10.

15. Hawksworth, J., Berriman, R., Goel, S.: Will Robots Really Steal our Jobs? An International Analysis of the Potential Long Term Impact of Automation. Political Science. London (2018) https://www.pwc.com/hu/hu/kiadvanyok/assets/pdf/impact _of_automation_on_jobs.pdf. 